\title{
Thermographic Inspection at the Interface of Dry Sliding Surfaces
}

\author{
G. Cuccurullo, V. Spingi, V. D'Agostino, R. Di Giuda and A. Senatore \\ Department of Industrial Engineering, University of Salerno \\ Italy
}

\section{Introduction}

During the last decades, in order to clarify the coupled thermal and frictional aspects in dry sliding contacts, researchers have been involved in theoretical models as well as in experimental testing. In order to outline both the analytical and the experimental approach, a procedure for estimating the maximum temperature increase in dry sliding contacts is introduced. The procedure is based on an analytical solution for the two-dimensional temperature field in a slab subjected to a suitably shaped moving heat source. Experiments were carried out on a specifically designed pin-on-disk device with the aim of taking into account the unavoidable uneven friction distribution under the coupled surfaces. The subsequent data reduction led to quite satisfactory agreement with analytical predictions and provided a suitable shape for the heating source distribution thus allowing for proper maximum temperature rise estimate. Since measuring the interface temperature of a friction pair is a difficult task, temperature data were collected by means of infrared thermography; this technique seems to be the most effective and valuable due to its ability of performing continuous temperature map recording with relatively high resolutions when compared to other traditional methods. It is a matter of facts that high energy rates are dissipated by friction during short periods, thus transient and localized thermal phenomena with high thermal gradients are to be expected. The latter conditions still suggest the use of IR thermography.

\section{Tribological remarks}

It is well known that the dynamic temperature distribution arising at the interface of dry sliding contacts has a strong influence in friction phenomena, thus the interface temperature characterization, from an engineering point of view, has always been an imperative topic in machine design.

Today, the heat production assessment is classified among the essential problems in the tribological behaviour of a broad mechanical devices area yet. Among them, a relevant role is played by dry contact friction phenomena, that is the ones featured by the absence of coherent liquid or gas lubricant film between the two coupled solid body surfaces. In fact, dry contacts, while performing in many components (brakes, clutches) an active role, in many kinematics and under specific operating conditions play also a passive role; this often 
results in harmful processes, such as undesirable temperature rise that can induce thermomechanical stress. It follows, therefore, the need to reduce their effects by means of more sophisticated projects requiring, for instance, the use of lubricants, of more suitable materials, design and operating conditions. However, it's well known that the heat transfer has also notable impact for fully developed hydrodynamic lubrication since it strongly modifies the oil viscosity and in severe cases may lead to oil film rupture. Nevertheless, in the case of hydrodynamic lubrication, the modelling approach is completely different, since the heat transfer mechanism is mainly convective at the oil film interface.

\section{Sliding contact interfaces}

Since pioneering studies, it is well known that the friction at sliding contact interfaces where two surfaces come together generates heat and most of this heat is conducted away through local rubbing asperities. It then understands how temperature field at the interface of dry sliding contacts has a strong influence on friction phenomena. Thus, much work has been done in the past in order to investigate this aspect. The theoretical approach encompasses finite element analysis, (Kennedy, 1981; Salti \& Laraqi, 1999) or analytical solutions, even transient ones based on a Fast Fourier Transform method, (Gao et al., 2000; Stanley \& Kato, 1997). Blok (Blok, 1937) first proposed the concept of flash temperature and derived simplified formulas for the maximum temperature rise on moving surfaces. Jaeger (Jaeger, 1942) formalized the mathematical models for the flash temperature on a semi-infinite medium for moving uniform rectangular heat sources. Many other flash temperature models have already appeared in the literature. These studies extended Jaeger's theory to various heat source shapes and to multiple asperity contact based on steady-state conditions (Archard, 1959; Francis, 1971; Laraqi et al., 2009; Kuhlmann-Wisdorf, 1987).

With reference to the experimental approach, as expected, it is strongly desirable to measure interface temperature during actual friction braking tests so that precise operating conditions were known for design purposes. However, measuring the interface temperature of a friction pair is a difficult task. Several methods have been reported (Dinc et al.,1993), but infrared measurements seem to be the most effective (Anon, 1995, Cuccurullo et al., 2010).

Some conclusions are well established. It is a matter of facts that high energy rates are dissipated by friction during short periods, thus transient and localized thermal phenomena with high thermal gradients such as hot bands and hot spots are to be expected, (Anderson \& Knapp, 1990; Panier et al., 2004); it is also clear that when surfaces slide over one another, the static contacts can change in time due to tangential load effects on junction growth, thermal expansion, wear, chemical oxidation or a variety of other physical phenomena (Vick et al., 1998), but also due to the actual complexity of the real area of contact between sliding surfaces (Vick \& Furey, 2001). Many thermal problems associated with brake friction pairs, including performance variation (fade, speed sensitivity) and rotor damage (heat spotting and thermal cracking) can be analysed in terms of localized frictional heat generation (Day et al., 1991).

In addition, it has been known for some time that the friction intensity is not distributed evenly across the surface of friction pair and that the local friction intensity of an imaginary friction lining segment changes in the course of the friction process (Barber, 1967; Rhaim et al., 2005; Severin \& Dörsch, 2001). Among the parameters yielding to uneven friction 
intensity, many authors ascribe great importance to the pressure distribution. It's well known that the pad wear is greater on the leading side and, according to the Reye's theory which states the proportionality between friction work and wear, the pressure distribution is expected to have its centre on the leading side. The calculations through free body diagrams of the dynamic centre of pressure $(\mathrm{CoP})$ position have been shown (Fieldhouse et al., 2006) for a brake pad during a normal braking operation, both in radial and axial directions. In fact, there is an interaction between frictional effects at the pad abutment between pad backplate and caliper finger. It has also been shown that the position of reaction force of the pad, which identifies the center of pressure to provide equilibrium, depends on friction level at pad/disc interface and the one at pad/abutment side of the caliper. The combination of these parameters normally yields to a leading centre of pressure and this effect is more marked at low brake pressure levels. The same authors have realized the complex task of measuring the interface pressure distribution during braking by means of a pressure sensitive film within the pad. Further experimental results have been achieved on a modified 12-pistons opposed calliper equipment (Fieldhouse et al., 2008). Tests were carried out at different levels of speed by applying uniform actuation pressure on the calliper side. The results about the pressure maps at pad/disk interface have shown that the position of the centre of the pressure moves considerably during a braking event, both radially and axially along the pad. Furthermore, it has been shown that under light braking with an uniform actuation pressure, the centre of pressure will always tend to be leading. It has been also demonstrated that, for increasing pressure and speed, the CoP tends to move towards the central region of the pad; moreover, the $\mathrm{CoP}$ position is more influenced by the level of the pressure than by the speed one. Recent studies have shown that one of the possible reasons for the variation in contact pressure distribution during braking is due brake pad surface topography. Some authors, in particular, examined six different pad configurations (Rahim et al.); even in this work, in order to measure contact pressure distributions, a suitable type of sensor film for a defined range of a local contact pressure have been chosen. Then a linear gauge has been used to measure brake pad topography. The test results have been proved that each pad has a different surface topography despite being produced by the same manufacturer; this indicates that when the pairs of pads are fitted in the brake system, it may produce different contact pressure distribution and consequently may generate different braking torque.

Another essential aspect responsible for the uneven friction distribution is to be related to the metal particles that originate from the drum or disk and diffuse into the bound friction layer, (Severin \& Musoil, 1995). Of course, the dynamical positioning and arrangement of the coupled surfaces can lead to unpredictable friction distribution during the occurrence of the sliding contact.

Since all the addressed issues can be related to uneven friction distribution, one of the major objective of the following work is to introduce a parameter, the engagement between the coupled surfaces, encompassing the addressed effects and being able to reproduce them in an equivalent fashion in the proposed theoretical framework. More general, the proposed analytical solution aims to explore the influence of the key problem parameters (geometry, materials, boundary and operating conditions) on the dry contact thermal response. Then a procedure has been setup in order to obtain a reliable estimation of the maximum temperature attained under the contact area. With reference to selected experimental 
evidences, interesting indications have been obtained since the agreement between analytical and experimental data is quite satisfactory.

\section{Basic equations and analytical solution}

The theoretical model used to predict the temperature rise due to a moving heat source is shown schematically in Fig. 1. A finite thickness slab is subjected to a heat source featured by linearly varying distribution, whose variable slope is the engagement, $\mu$. The reference system is attached to the source moving with constant velocity $U$ in the $y$-direction and supposed to be due to the frictional effect at the interface. The slab is cooled by radiativeconvective heat transfer $(\mathrm{h})$ to an ambient at uniform temperature while it is adiabatic on the lower surface. The slab is subjected to thermal coupling conditions on the remaining edges $(y= \pm L)$. For such a problem, if the observer is travelling on with the source and if a suitable time has elapsed, the energy balance equation and the related boundary conditions turn out to be time-independent and fully developed temperature field is attained. Then the problem can be written in dimensionless form as:

$$
\begin{gathered}
\frac{\partial^{2} \vartheta}{\partial \xi^{2}}+\frac{\partial^{2} \vartheta}{\partial \eta^{2}}+2 \omega \frac{\partial \vartheta}{\partial \eta}=0 \\
\vartheta\left(\xi, \eta \rightarrow-\eta_{L}\right)=\vartheta\left(\xi, \eta \rightarrow \eta_{L}\right) \\
\left.\frac{\partial \vartheta}{\partial \eta}\right|_{\xi,-\eta_{L}}=\left.\frac{\partial \vartheta}{\partial \eta}\right|_{\xi, \eta_{L}} \\
\left.\frac{\partial \vartheta}{\partial \xi}\right|_{0, \eta}=\operatorname{Bi} \vartheta(0, \eta)-f(\eta) \\
\left.\frac{\partial \vartheta}{\partial \xi}\right|_{1, \eta}=0
\end{gathered}
$$

where: $\xi=x / s_{x} ; \eta=(y-U t) / s_{x} ; \theta=\left(T-T_{a}\right) /\left(s_{x} \dot{\mathrm{q}}_{0} / k\right), k$ being the slab conductivity; $\omega=s_{x}$ $\mathrm{U} /(2 \alpha)$ is the Peclet number, $\alpha$ being the slab diffusivity. The source intensity is assumed to be described such as $\dot{\mathrm{q}}(\mathrm{y})=\dot{\mathrm{q}}_{0} \mathrm{f}(\mathrm{y})$, where $\dot{\mathrm{q}}_{0}$ is the heat flux intensity at the origin and $\mathrm{f}(\mathrm{y})$ represents its spatial distribution which, for the present purposes, is assumed to be linear: $\mathrm{f}(\mathrm{y})=1+\mu \mathrm{y} / \mathrm{s}_{\mathrm{y}}$, the parameter $\mu$ being responsible for the variable slope and thus for the pin to disk engagement. Finally, $\mathrm{Bi}=\mathrm{h} \mathrm{s}_{\mathrm{x}} / \mathrm{k}$ is the Biot number.

According to Blok's postulate, i.e. the energy balance at the contact interface, the total heat generated by friction is the sum of the heat flux entering the pin and the one entering disk. Thus, $\dot{\mathrm{q}}(\mathrm{y})$ represents the local heat flux entering the disk. Wishing to extend the problem to encompass the pin thermal behaviour, the heat flux entering the pin is usually modelled assuming 1D heat transfer according to the thin rod model, which is suggested by the typical pin geometries. Thermal coupling conditions are usually considered imposing the continuity of the average temperature at the interface contact area, i.e. the perfect thermal 


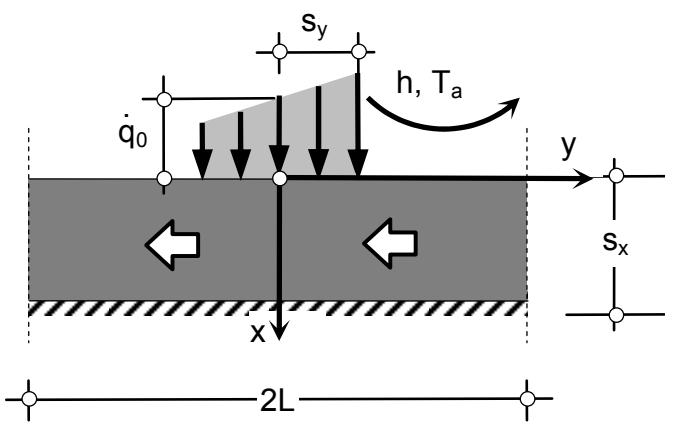

Fig. 1. Sketch of the problem

contact between the coupled surfaces. For usual geometries and materials, it can be stated that, the heat flux evacuated by the disk is much greater than that evacuated by the pin (Laraqi et al., 2009).

The two-dimensional temperature field has been solved analytically in closed form by Fourier series; in particular the structure for the temperature field has been sought to be:

$$
\vartheta(\xi, \eta)=\sum_{k=-\infty}^{\infty} Q_{k}(\xi) e^{i \Omega k \eta}
$$

where $\Omega=\pi s_{x} / L$. The unknown $Q_{k}(\xi)$ functions are derived by imposing the assumed structure to satisfy the above set of equations:

$$
\begin{gathered}
\mathrm{Q}_{\mathrm{k}}{ }^{\prime \prime}+\left(2 \omega \mathrm{i} \Omega \mathrm{k}-\Omega^{2} \mathrm{k}^{2}\right) \mathrm{Q}_{\mathrm{k}}=0 \\
\mathrm{Q}_{\mathrm{k}}{ }^{\prime}(0)=\mathrm{BiQ}_{\mathrm{k}}(0)-\mathrm{F}_{\mathrm{k}} \\
\mathrm{Q}_{\mathrm{k}}{ }^{\prime}(1)=0
\end{gathered}
$$

where :

$$
F_{k}=\frac{s_{x}}{2 L} \int_{-L / s_{x}}^{L / s_{x}} f(\eta) e^{-i \Omega k \eta} d \eta
$$

is the k-th component of the transformed wall heat flux.

\section{Experimental setup}

In order to characterize the friction between solids, all the tests were performed on a pin-ondisk braking system specifically designed; it is a classical wear rigs and essentially consists in a cylindrical pin in eccentric contact with a rotating disk, Fig. 2.

During each test, the disc is rotated at constant speed by an electric motor controlled by an hydraulic regulator; two stationary pin specimens are symmetrically pressed against the 


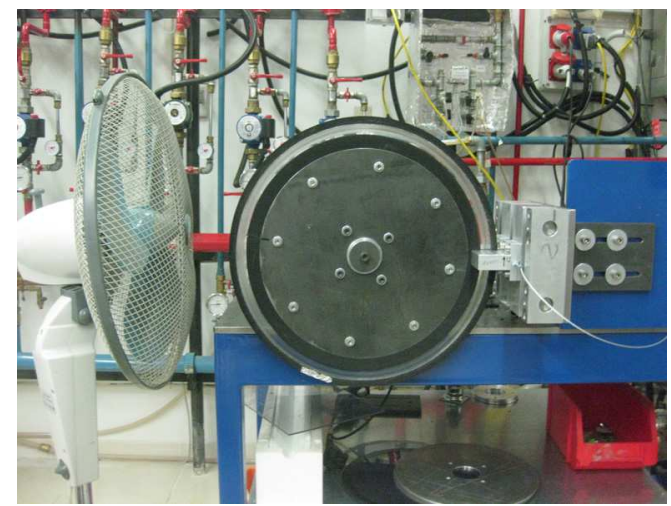

Fig. 2. Experimental setup

disk. The pins are made of a commercial braking material and are featured by cylindrical shape with $5.5 \mathrm{~mm}$ radius. Two $20 \mathrm{~cm}$ radius discs made of polycarbonate (5 mm thickness) and bakelite (4 mm thickness) were used. In order to closely recover the model assumptions, both disk surfaces where insulated with the exception of a path allowing pin motion. A weight device allows to control the axial pin load. Each test was configured by setting pinload and disk angular speed. A large value of the pin eccentricity was considered in any test taking care to realize a sufficient distance from the outer radius such as to avoid edge effects. It can be shown that, under such operating conditions, the curvature effects are negligible and thus the model at hand can be properly used (Laraqi, 2009).

Provided a suitable emissivity calibration, the thermal pattern left on the disk by the track due to the relative pin motion is detected by an IR camera. The IR equipment (Thermacam Flir P65) exhibits a spatial resolution of about $30 \mathrm{dpi}$, due to $320 \times 240$ pixel matrix, the operating distance and optics in use. A specifically designed software allows to extract from the IR image the temperature profile to process: this latter is pointed out as the one where the radial slope is zero along the thermal pattern left on the disk.

A typical infrared image is reported in Fig. 3. Here it is possible to appreciate that the pinholder partially covers the pin-track thermal patterns. As a consequence, it was possible to

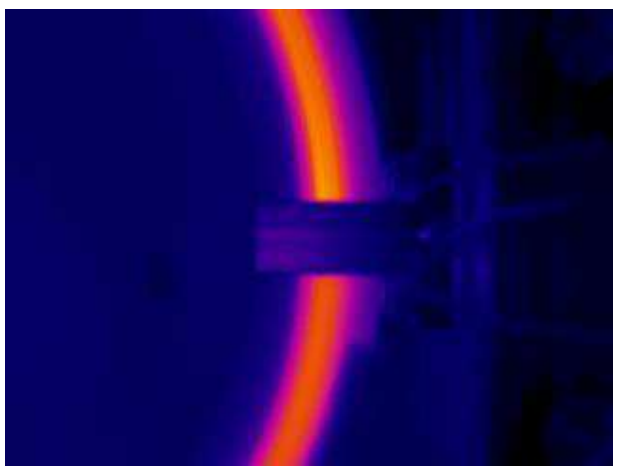

Fig. 3. A typical thermogram 
detect temperatures along a track with the exclusion of an area $3 \mathrm{~cm}$ wide along the circumferential pin-track and placed around the pin itself. It can be argued that the presence of the pin-holder always interferes with optical measurements; however it will be shown later that a suitable data reduction can be done to reconstruct the hidden portion of the temperature profile at hand.

\section{Data reduction and simulation}

When performing measurements, it is assumed that temperature rise on the loaded surface is described by the temperature distribution given by the above model, after thermal equilibrium is attained. Due to the complexity of the response model, the Levenberg Marquadt technique $\chi^{2}$ based fitting method has been selected. The technique enables to process non linear models with an arbitrary number of parameters. Thus, the optimal choice for matching experimental and theoretical data is accomplished by minimizing the $\chi^{2}$-merit function:

$$
\chi(\underline{a})=\sum_{i=1}^{N}\left[T_{i}-T\left(y_{i}, \underline{a}\right)\right]^{2}
$$

where the $\mathrm{N}$ experimental data points, $\left(\mathrm{T}_{\mathrm{i}}, \mathrm{y}_{\mathrm{i}}\right)$, are to be detected by means of IR thermography along the circular pattern left on the disk surface by the pin; the function $\mathrm{T}\left(\mathrm{y}_{\mathrm{i}}\right.$, $\underline{\mathrm{a}})$ is the functional relationship given by the model for the disk surface temperature, $\underline{a}=(\mathrm{h}$, $\mu, \dot{\mathrm{q}}_{0}$ ) being the unknown-parameters vector.

The accuracy of the fitting in estimating the unknown thermal parameters was tested on Montecarlo simulated thermograms to obtain confidence interval width of the fitted parameters for fixed operative conditions.

Simulated thermograms were obtained by perturbing reference analytical surface temperature profiles with a noise level due to a randomly generated maximum uncertainty of $\pm 1^{\circ} \mathrm{C}$. As an example in Fig. 4, a fixed reference temperature profile (continuous line) has been perturbed to obtain a discrete number of simulated experimental temperatures, i.e. the dots in Fig. 4; processing the perturbed profile with the $\chi^{2}$ fitting, a set of the three unknown parameters was estimated, thus allowing to reconstruct analytically the reference profile, i.e. the dashed curve in the figure.

In order to realize the reference profile, some parameters were fixed having in mind the experimental setup, namely: $\mathrm{T}_{\mathrm{a}}=23.5^{\circ} \mathrm{C}, \mathrm{s}_{\mathrm{x}}=2.5 \mathrm{~mm}, \mathrm{~s}=5.5 \mathrm{~mm}, \mathrm{~h}=32.5 \mathrm{~W} /\left(\mathrm{m}^{2} \mathrm{~K}\right), \mathrm{L}=56$ $\mathrm{cm}, \mathrm{U}=0.28 \mathrm{~m} / \mathrm{s}$ while the engagement was set equal to 0.7 . Spatial resolution was assumed to be fixed at the best allowed by the camera and optics in use, i.e. 30 dpi. Then, the simulation took place by considering twenty different configurations for performing data reduction: each configuration was based on processing pin-track bands all starting from $-\left(\mathrm{s}_{\mathrm{y}}\right.$ $\left.+3 s_{x}\right)$, i.e. the first detectable point free from the pin-holder shielding, and increasing widths by $s_{x}$-steps. Suitable dimensionless temperature profiles were processed, in such way only two unknowns are to be estimated, i.e. the Biot number and the pin-disk engagement. Results are shown in Figs. 4 and 5 where the mean values of the Biot number and of the engagement parameter are reported for the twenty increasing bandwidth extensions, each one identified by a progressive band index. For each band index, figures also report the 


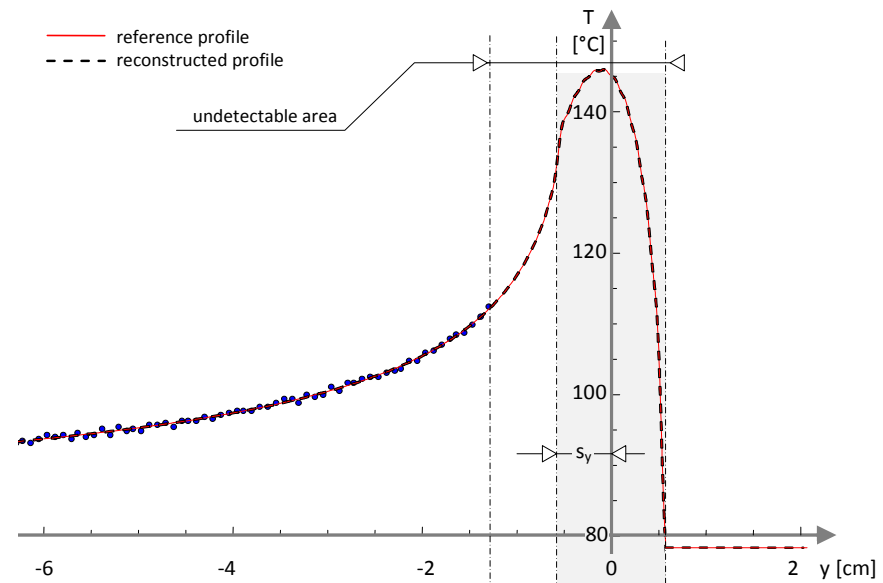

Fig. 4. Reference, simulated and resulting temperature profiles

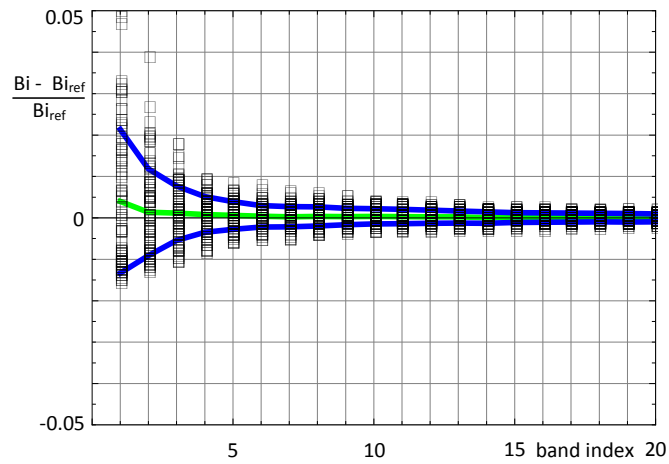

Fig. 5. Simulation results for $\mathrm{Bi}$

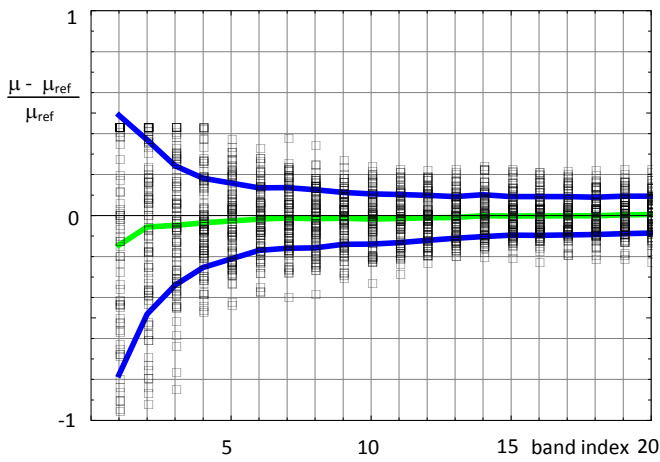

Fig. 6. Simulation results for $\mu$ 
estimated percentage parameters deviation from the corresponding reference values and the $63 \%$ confidence limit. Since the resulting standard deviation practically attains fixed values, it can be concluded that both for the former and the latter parameter there is no improvement if bandwidths larger than $8 \mathrm{~s}_{\mathrm{x}}$ are considered. The sensitivity on the Biot number seems to be higher than the one on the pin-on-disk engagement, at least around the reference preset values. The latter effect can be explained considering that Biot number controls the slab energy level.

\section{Selected experimental tests}

Experimental tests presented in the following were carried on by considering two angular disk-speeds corresponding to peripheral values of $U_{1}=0.28 \mathrm{~m} / \mathrm{s}$ and $U_{2}=0.57 \mathrm{~m} / \mathrm{s}$. The latter values were calculated considering the radial collocation of the pin cylindrical axis, that is $17.7 \mathrm{~cm}$. The pin-load considered was $30 \mathrm{~kg} / \mathrm{cm}^{2}$ for the former test and $20 \mathrm{~kg} / \mathrm{cm}^{2}$ for the latter. The circumferential thermal pattern extracted according to the procedure reported in paragraph 5 , after data reduction procedure gave for the polycarbonate disk: $\underline{\mathrm{a}}_{1}=\left\{\mathrm{h}_{1}=32.5 \mathrm{~W} /\left(\mathrm{m}^{2} \mathrm{~K}\right), \mu_{1}=0.7, \dot{\mathrm{q}}_{0,1}=1.9710^{5} \mathrm{~W} / \mathrm{m}^{2}\right\}$ for the $30 \mathrm{~kg} / \mathrm{cm}^{2} \mathrm{load} ; \mathrm{a}_{2}=\left\{\mathrm{h}_{2}=\right.$ $\left.32.5 \mathrm{~W} /\left(\mathrm{m}^{2} \mathrm{~K}\right), \mu_{2}=0.7, \dot{\mathrm{q}}_{0,2}=3.1110^{5} \mathrm{~W} / \mathrm{m}^{2}\right\}$ for the $20 \mathrm{~kg} / \mathrm{cm}^{2}$ load. Such values were used to build the analytical profiles in Figs. 7 and 8: the agreement with experimental points seems to be quite satisfying. It has to be underlined that the estimated maximum values attained by temperature under the contact area, hidden to the IR camera view, are 145.6 and $203.1^{\circ} \mathrm{C}$, respectively. Both values are far beyond the nearest detectable temperatures, namely 111.4 and $157.1^{\circ} \mathrm{C}$. It appears that the region under the contact area is a critical one due to the occurrence of high thermal gradients which could lead to get wrong temperature estimates. Finally, a first check about $\dot{\mathrm{q}}_{0}$-values shows that they satisfyingly agree the expected dry friction characteristic.

The same trends outlined before were recovered for bakelite disk undergoing different average operating pin-loads, namely 0.93 and $1.4 \mathrm{MPa}$, for the two selected speeds fixed before. Figures from 8 to 12 report the data reduction output related to the four different combinations of the addressed parameters. It is to be underlined that the resulting values of the engagement parameter attain values very close to the unity for all the tests, thus showing that heat dissipation profile is shaped so to exhibit higher values toward the leading front.

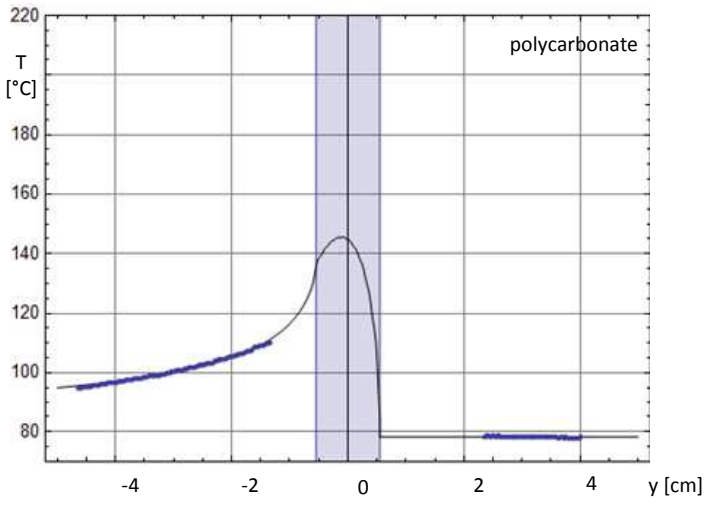

Fig. 7. Results for $0.28 \mathrm{~m} / \mathrm{s}, 30 \mathrm{~kg} / \mathrm{cm}^{2}$ 


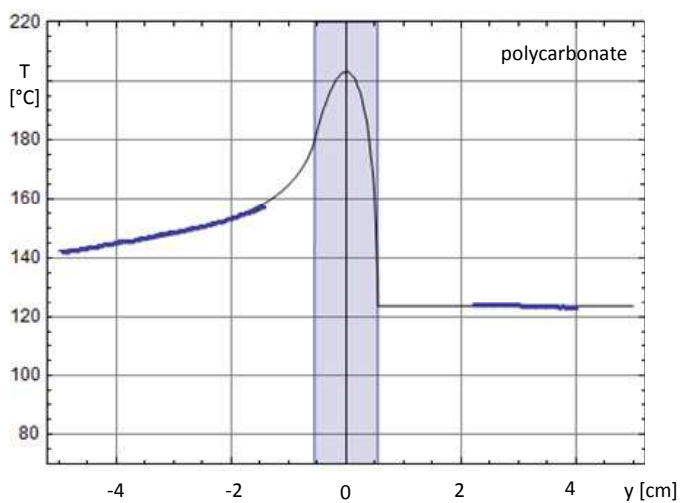

Fig. 8. Results for $0.57 \mathrm{~m} / \mathrm{s}, 20 \mathrm{~kg} / \mathrm{cm}^{2}$

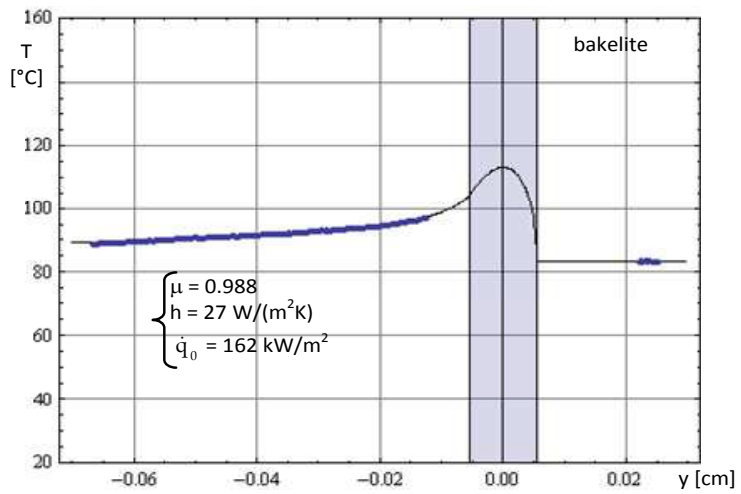

Fig. 9. Results for $0.57 \mathrm{~m} / \mathrm{s}, 0.93 \mathrm{MPa}$

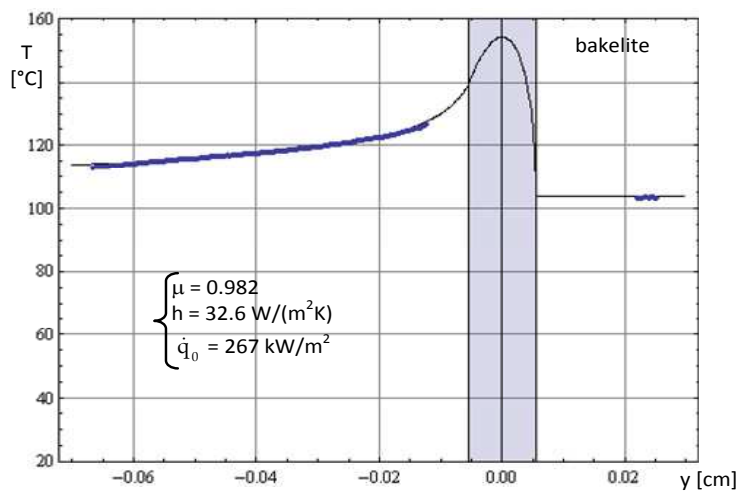

Fig. 10. Results for $0.57 \mathrm{~m} / \mathrm{s}, 1.4 \mathrm{MPa}$ 


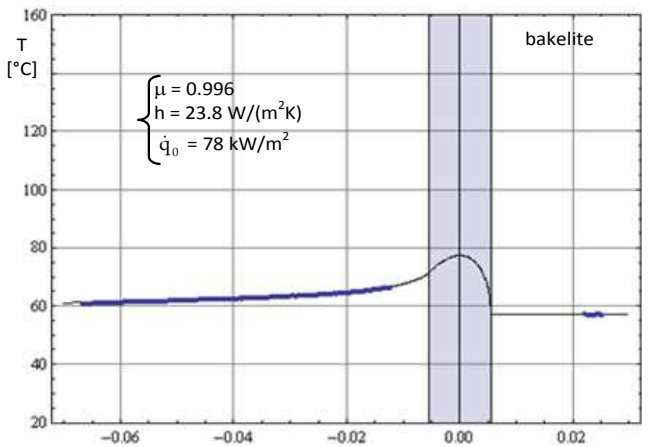

Fig. 11. Results for $0.28 \mathrm{~m} / \mathrm{s}, 0.93 \mathrm{MPa}$

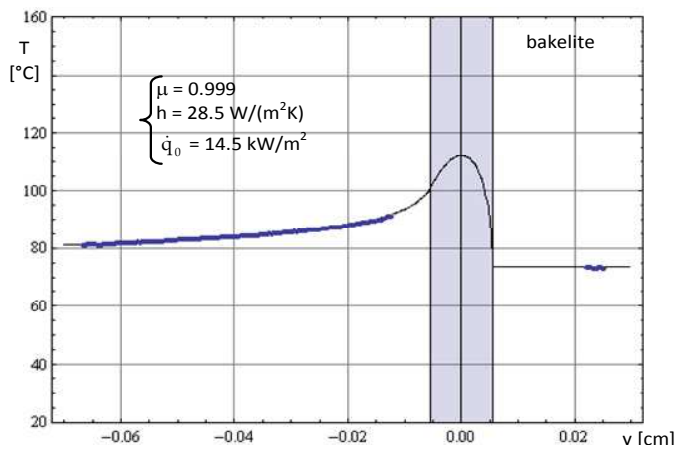

Fig. 12. Results for $0.28 \mathrm{~m} / \mathrm{s}, 1.4 \mathrm{MPa}$

\section{Conclusion}

Having in mind to feature the maximum temperature rise in dry sliding contacts, both the classical experimental and analytical approaches have been run. The dimensionless analytical model allows to take in to account the effect of the relative speed, thermal boundary conditions, disk thickness and material making use of only few parameters. It is simple to encode in any commercial software since the rectilinear motion description involves the use of trigonometric functions.

From experimental point of view, IR thermography revealed itself to be a valuable tool while an attempt to take into to account the uneven friction distribution has been done by introducing the engagement parameter. The latter is able to realize a suitable heating distribution shape. A quite satisfying agreement between analytical and experimental predictions was realized, thus a reliable estimate has been obtained for the maximum temperature under the contact area, where direct measuring is always critical.

\section{References}

Anderson, A.E., \& Knapp, R.A. (1990). Hot spotting in automotive friction systems, Wear, $135,319-337$. 
Anon (1995), Material development using infrared thermography, Metallurgia 62, 409-410. Archard, J.F (1959). The temperature of rubbing surfaces, Wear, 2, 438-455.

Barber, J.R (1967). The influence of thermal expansion on the friction and wear process, Wear, 10: 155-159.

Blok, H. (1937). Theoretical study of temperature rise at surfaces of actual contact under oiliness lubricating conditions, Proc. of the Institute of Mechanical Engineers General Discussion of Lubrication, London: Institute of Mechanical Engineers.

Cuccurullo, G., D'Agostino, V., Di Giuda, R. \& Senatore, A. (2010). An Analitycal Solution and an Experimental Approach for Thermal Field at the Interface of Dry Sliding Surfaces, Meccanica, 46, 589-595, ISSN 0025-6455.

Day, A.J., Tirovic M. \& Newcomb T.P. (1991). Thermal effects and pressure distributions in brakes, Proceedings of the Institution of Mechanical Engineers,205.

Dinc, O.S.C., Ettles, M., Calabrese, S.J. \& Scarton, H.A. (1993). The measurement of surface temperature in dry or lubricated sliding, Journal of Tribology, 115, 78-82, ISSN 0022-2305.

Fieldhouse, J.D, Ashraf, N. \& Talbot, C. (2006). Measurement of the dynamic centre of pressure of a brake pad during a braking operation, SAE Technical Papers, 2006-01-3208.

Fieldhouse, J.D., Ashraf, N. \& Talbot, C. (2008). The measurement and analysis of the $\mathrm{disc} / \mathrm{pad}$ interface dynamic centre of pressure and its influence on brake noise, SAE Technical Paper, 2008-01-0826.

Francis, H.A. (1971). Interfacial temperature distribution whitin a sliding hertzian contact, ASLE Trans., 14, 41-54.

Gao, J., Lee, C., Ai, X. \& Nixon, H. (2000). An FFT-Based Transient Flash Temperature Model for General Three-Dimensional Rough Surface Contacts, Journal of Tribology, 122, 519-523, ISSN 0022-2305.

Jaeger, J.C. (1942). Moving sources of heat and the temperature at sliding contacts. Journal Soc. NSW, 76, 203-24.

Kennedy, F.E. (1981). Surface temperatures in sliding systems: a finite element analysis. Journal of Lubr. Technol., 103, 90-96.

Kuhlmann-Wisdorf, D. (1987). Temperatures at interfacial contact spots: dependence on velocity and one role reversal of two materials in sliding contact, Journal of Tribology, 109,321-329.

Laraqi, N., Alilat, N. Garcia De Maria, J. M. \& Bairi, A. (2009). Termperature and division of heat in a pin-on-dsik frictional device-exact analytical solution, Wear ,266, 765-770.

Panier, S., Dufrenoy, P. \& Weichert, D. (2004), An experimental investigation of hot spots in railway disc brakes, Wear, 256, 764-773.

Rhaim, A., Bakar, A. \& Ouyang, H. (2005). Brake pad surface topography part I: contact pressure distribution, SAE Technical Paper, 2005-01-3941.

Salti, B. \& Laraqi N. (1999). Surface temperatures in sliding systems: a finite element analysis, Int. Journal of Heat and Mass transfer, 42, 2363-2374.

Severin, D. \& Dörsch, S., Friction mechanism in industrial brakes, Wear, 249: 771-779, 2001.

Severin, D., Musiol, F. (1995). Der Reibprozess in trockenlaufenden mechanischen Bremsen und Kupplungen, Konstruktion, 47, 59-68.

Stanley, H.M. \& Kato, T. (1997). An FFT-based method for rough surface contact, T. ASME Journal of Tribol., 119, 481-485, ISSN 0022-2305.

Vick, B. \& Furey, M.J. (2001). A basic theoretical study of the temperature rise in sliding contact with multiple contacts, Tribology International, 34, 823-829.

Vick, B., Furey, M.J. \& Iskandar, K. (1998). Surface temperatures and tribological behavior of pure metallic elements, Proc. of the Fifth International Tribology Conference, Austrib'98, Brisbane (Australia). 


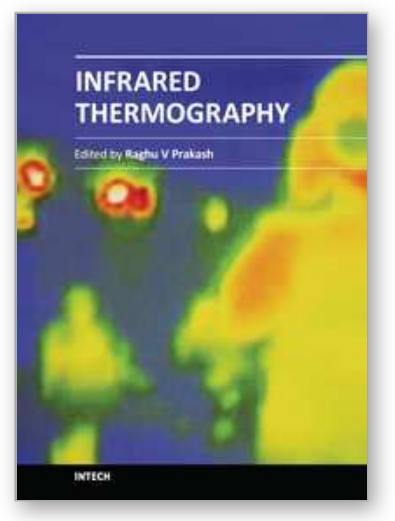

\author{
Infrared Thermography \\ Edited by Dr. Raghu V Prakash
}

ISBN 978-953-51-0242-7

Hard cover, 236 pages

Publisher InTech

Published online 14, March, 2012

Published in print edition March, 2012

Infrared Thermography (IRT) is commonly as a NDE tool to identify damages and provide remedial action. The fields of application are vast, such as, materials science, life sciences and applied engineering. This book offers a collection of ten chapters with three major sections - relating to application of infrared thermography to study problems in materials science, agriculture, veterinary and sports fields as well as in engineering applications. Both mathematical modeling and experimental aspects of IRT are evenly discussed in this book. It is our sincere hope that the book meets the requirements of researchers in the domain and inspires more researchers to study IRT.

\title{
How to reference
}

In order to correctly reference this scholarly work, feel free to copy and paste the following:

G. Cuccurullo, V. Spingi, V. D’Agostino, R. Di Giuda and A. Senatore (2012). Thermographic Inspection at the Interface of Dry Sliding Surfaces, Infrared Thermography, Dr. Raghu V Prakash (Ed.), ISBN: 978-953-510242-7, InTech, Available from: http://www.intechopen.com/books/infrared-thermography/thermographicinspection-at-the-interface-of-dry-sliding-surfaces

\section{INTECH}

open science | open minds

\section{InTech Europe}

University Campus STeP Ri Slavka Krautzeka 83/A 51000 Rijeka, Croatia Phone: +385 (51) 770447

Fax: +385 (51) 686166 www.intechopen.com

\section{InTech China}

Unit 405, Office Block, Hotel Equatorial Shanghai No.65, Yan An Road (West), Shanghai, 200040, China 中国上海市延安西路65号上海国际贵都大饭店办公楼405单元 Phone: +86-21-62489820

Fax: +86-21-62489821 
(C) 2012 The Author(s). Licensee IntechOpen. This is an open access article distributed under the terms of the Creative Commons Attribution 3.0 License, which permits unrestricted use, distribution, and reproduction in any medium, provided the original work is properly cited. 